\title{
STUDIES TOWARDS HEMOCOMPATIBILITY OF POLYAMINE CONJUGATES WITH BICYCLIC SYSTEMS
}

\author{
MARTA SZUMILAK ${ }^{*}$, MAGDALENA MARKOWICZ-PIASECKA², \\ ELŻBIETA MIKICIUK-OLASIK ${ }^{2}$, ANDRZEJ STAŃCZAK ${ }^{1}$ and JOANNA SIKORA²
}

${ }^{1}$ Department of Hospital Pharmacy, Faculty of Pharmacy, Medical University of Lodz, 1 Muszyńskiego Street, 90-151 Łódź, Poland,

${ }^{2}$ Department of Pharmaceutical Chemistry, Drug Analysis and Radiopharmacy, Medical University of Lodz, 1 Muszyńskiego Street, 90-151 Łódź, Poland

\begin{abstract}
Assessing hemocompatibility of anticancer drug candidate is a very important task due to the fact that coagulation disorders are often correlated with malignancy or induced by chemotherapy. The aim of this study was to examine the influence of some polyamine conjugates with bicyclic systems on the process of coagulation and fibrinolysis. In addition, their effect on the healthy human erythrocytes (RBCs) was assessed. Prothrombin Time (PT), Activated Partial Thromboplastin Time (APTT), clot formation and lysis test (CL-test) were performed to evaluate the influence of some polyamine conjugates on plasma hemostasis. The effects of tested compounds on RBCs were assessed using hemolysis assays and microscopy studies. APTT and PT examinations revealed that all tested compounds apart from the highest concentrations of compounds 3 and 5 did not exert significant effects on intrinsic and extrinsic coagulation pathways. Despite their substantial influence on the kinetic parameters of the process of clot formation and fibrinolysis, the examined compounds, over the entire concentration range, did not alter the overall potential of clot formation and lysis $\left(\mathrm{CL}_{\mathrm{AUC}}\right)$ suggesting that they might be regarded as biocompatible concerning plasma hemostasis. At potential therapeutic concentrations (constituting $\mathrm{IC}_{50}$ value for MCF-7 cells) tested polyamine conjugates showed no adverse effects on the membranes of RBCs. The promising antiproliferative activity of representative polyamine conjugates together with their hemocompatibility make them good anticancer drug candidates for further preclinical evaluation.
\end{abstract}

Keywords: coagulation, fibrinolysis, biocompatibility, erythrotoxicity, polyamine conjugates

The coagulation disorders are very frequent complication associated with various malignancies $(1,2)$. They can be clinically manifested by both thrombosis (3) and hemorrhage (4). Multiple factors responsible for coagulation system dysfunctions are related to malignant disease itself, patient characteristics as well as chemotherapy (5, 6). Antineoplastic drugs have the ability to induce alterations in hemostatic system independently from malignancy (7). It appears to be very important safety concern in cancer patients and may be even life-threatening (8). As reported by Khorana et al. thromboembolism is the leading cause of death in cancer patients with active disease on chemotherapy (9). Molecular mechanisms underlying chemotherapy-induced hemostatic alterations are multifactorial and complex (7). They include direct vascular endothelium injury or endothelial cells apop- tosis resulting in the hemostatic imbalance between endothelial tissue factor (TF) and tissue factor pathway inhibitor (TFPI) (10), the release of inflammatory cytokines from damaged tumor cells, alterations in levels of both anticoagulant and procoagulant molecules and platelet activation $(2,7)$. Furthermore, coagulation system abnormalities depend on the kind of chemotherapy regimen. Thrombotic events are concomitant with L-asparaginase (ASP) treatment in children with acute lymphoblastic leukemia (ALL) (11). Tamoxifen prophylaxis in ER-positive breast cancers results in statistically significantly higher rates of deep vein thrombosis (DVT) and pulmonary embolism (PE) (12). Disseminated intravascular coagulation (DIC) is characteristic for prostate cancer (13) but it can also develop in association with acute hemolysis during oxaliplatin infusion (14).

* Corresponding author: e-mail: marta.szumilak@umed.lodz.pl 
Moreover, using combinations of antineoplastic drugs with other types of anticancer agents e.g. antiangiogenic drugs may be correlated with a significantly increased risk of coagulation abnormalities (10). Thalidomide is associated with a significantly increased risk of deep vein thrombosis (DVT) when given in combination with multi-agent chemotherapy and dexamethasone (15-17).

Our quest for new compounds with anticancer activity is focused on symmetrical polyamine conjugates with various bicyclic terminal moieties varying in terms of the presence and the position of heteroatoms or functional groups. Their cytotoxic potential was evaluated in vitro towards the highly aggressive A375 melanoma cell line $(18,19)$ the PC-3 prostate adenocarcinoma cell line, the DU-145 prostate carcinoma cell line and the MCF-7 mammary gland adenocarcinoma cell line $(20,21)$. It was revealed that antiproliferative activity of polyamine conjugates strongly depends on their chemical structure as well as cancer cell line type. The most promising entities contain quinoline, chromane, naphthalene or indole scaffolds tethered by 1,4-bis(3-aminopropyl)piperazine, 3,3'diamino- $N$-methyldipropylamine or bis(3-aminopropyl)amine $(18,19,22)$. The lowest $\mathrm{IC}_{50}$ values 6.00 and $7.63 \mu \mathrm{M}$ were denoted for naphthalene derivatives $\mathbf{3}$ and $\mathbf{4}$, respectively when evaluated against MCF-7 cell line (20). Furthermore, it was elucidated that some quinoline $\mathbf{2}$ and naphthalene $\mathbf{3}$, 4 derivatives have the ability to interact with doublestranded DNA (ds-DNA) via an intercalative binding mode $(20,23)$. In case of quinoline moiety intercalation process was observed when 1,4-bis(3aminopropyl)piperazine was used as the linker while 3,3'-diamino- $N$-methyldipropylamine or bis(3-aminopropyl)amine were crucial to place naphthalene group in an optimal position for stacking interactions $(20,23)$.
Assuming that early in vitro studies assessing the influence of new molecules on healthy tissues may shed light on the future safety of the therapy, in the current work we decided to evaluate the effect of representative polyamine conjugates with bicyclic systems (1-6) (Fig. 1) on the process of coagulation and fibrinolysis using Activated Partial Thromboplastin Time (APTT) and Prothrombin Time (PT) as well as clot formation and lysis test (CL-test). In addition, their influence on the healthy human erythrocytes (RBCs) was established.

\section{EXPERIMENTAL}

\section{Examined compounds}

Compounds 1-6 used in this study were selected from previously synthesized and in vitro evaluated polyamine derivatives. Their synthesis and analytical data were described earlier (18-21). Compounds 2 and $\mathbf{6}$ as hydrochlorides were dissolved in water whereas compounds $\mathbf{1}, \mathbf{3}, \mathbf{4}$ and $\mathbf{5}$ were dissolved in dimethyl sulfoxide (DMSO). $\mathrm{IC}_{50}$ values of examined compounds (MCF-7 cell line) were as follows: 21.39 $\mu \mathrm{M}$ (1), $18.54 \mu \mathrm{M}$ (2), $7.48 \mu \mathrm{M}$ (3), $6.00 \mu \mathrm{M}$ (4), $15.51 \mu \mathrm{M}(5), 16.91 \mu \mathrm{M}(\mathbf{6})(20,21)$.

\section{Materials}

For the CL-test, thrombin was produced by Biomed (Poland) and recombinant tissue plasminogen activator (t-PA) by Boehringer-Ingelheim (Germany). Tris-buffered saline (TBS, cat. no. SRE0032) was purchased from Sigma Aldrich (Germany). For APTT assay we used Bio-Ksel System APTTs reagent and calcium chloride (BioKsel, Poland). Bio-Ksel PT plus reagent (thromboplastin and solvent) was used in PT tests. Triton X100 (cat. no. 841810492) and sodium chloride (cat. no. 794121116), used in the erythrotoxicity test were provided by Polish Chemical Reagents (Poland).<smiles>CN(CCCNC=C1C(=O)Nc2ccccc2C1=O)CCCNC=C1C(=O)Nc2ccccc2C1=O</smiles>

1<smiles>Nc1c(C(=O)NCCCN2C=CCN(CCCNC(=O)c3cnc4ccccc4c3N)CC2)cnc2ccccc12</smiles>
2<smiles>O=C(NCCCN(P)CCCNC(=P)c1ccc2ccccc2c1)c1ccc2ccccc2c1</smiles><smiles>CP(P)P</smiles>

Figure 1. Polyamine derivatives with bicyclic systems under study 

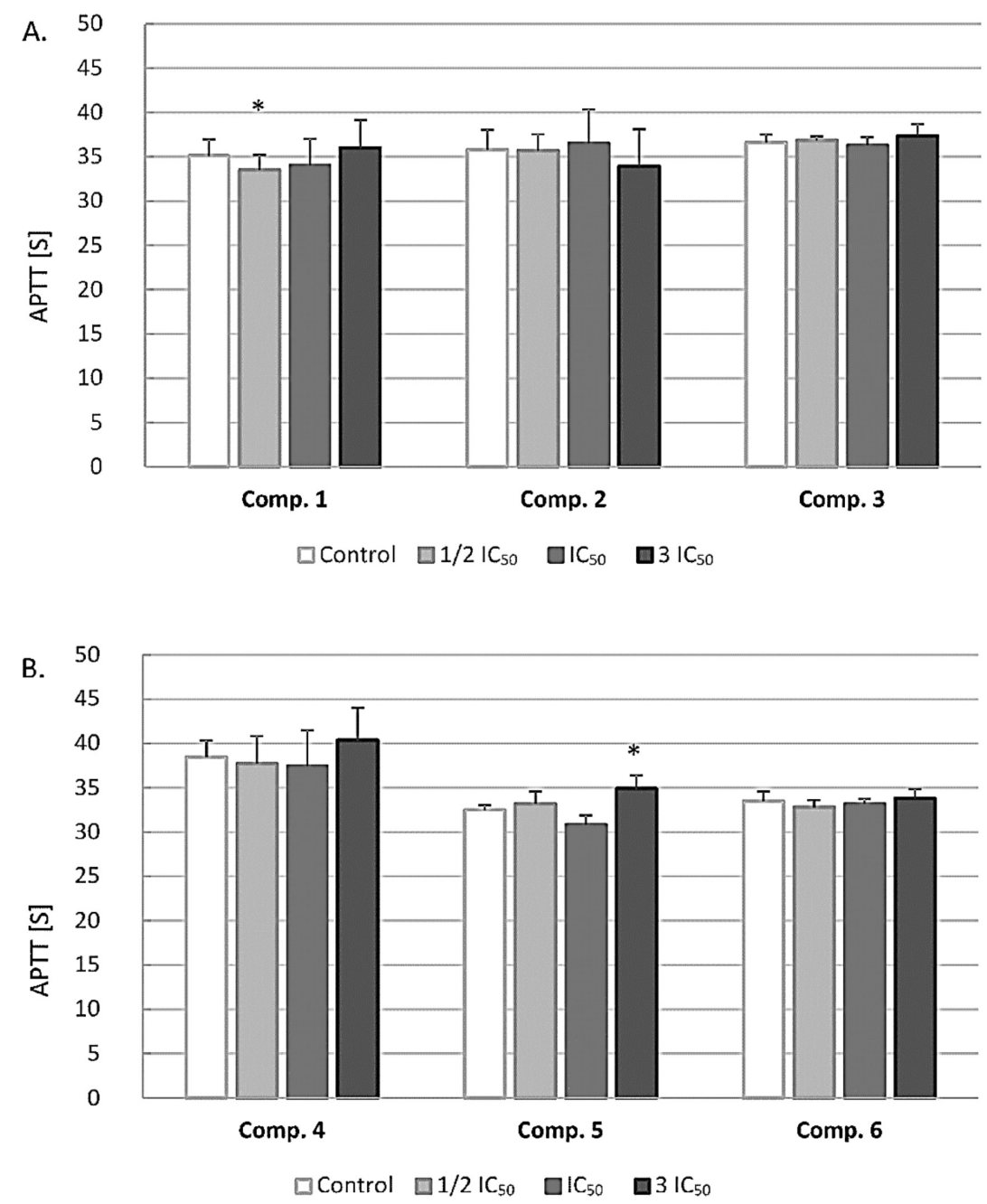

Figure 2. Effects of polyamine conjugates (A. - compounds 1-3; B. - compounds 3-6) on activated partial thromboplastin time (APTT) (mean \pm S.D.; $\mathrm{n}=5$ ) after 3 min incubation in plasma; final volume $160 \mu \mathrm{L} .{ }^{*} \mathrm{p}<0.05$ vs. control. Exposure to the tested compounds even at the highest concentrations was shown not to significantly influence the value of APTT over the whole concentration range apart from compound 5 which contributed to the significant prolongation of APTT at a concentration of $46.56 \mu \mathrm{M}$. Compound $\mathbf{1}$ at $10.69 \mu \mathrm{M}$ significantly shortened APTT

\section{Methods}

Plasma preparation for CL test, APTT, and PT measurements

Blood samples were obtained from healthy donors from the Blood Donation Centre in Lodz. Preparation of biological materials was described previously (24). The studies on the biological material were approved by the Bioethics Committee of the Medical University of Lodz (RNN/109/16/KE).

\section{Activated partial thromboplastin time (APTT)}

Activated partial thromboplastin time (APTT) assay was performed on coagulometer CoagChrom3003 Bio-Ksel (Poland) according to the commercial method. Results were presented as mean \pm SD (standard deviation); $\mathrm{n}=5$. The method was vali- dated on Bio-Ksel Normal and Abnormal plasma. The coefficient of variability was counted $(\mathrm{W}=$ $0.75 \%$ for Normal plasma, $\mathrm{W}=2.49 \%$ for Abnormal plasma).

The prothrombin time (PT), fibrinogen (FBG), international normalized ratio (INR)

PT test was conducted on coagulometer (CoagChrom-3003 Bio-Ksel, Poland) according to the commercially available method. The results were presented as mean $\pm \mathrm{SD} ; \mathrm{n}=5$. Reagent provides also a quantitative measurement of the fibrinogen concentration. The method was validated on Bio-Ksel Normal and Abnormal plasma. The coefficient of variability was counted $(\mathrm{W}=2.56 \%$ for Normal plasma, $\mathrm{W}=4.10 \%$ for Abnormal plasma). 


\section{CL-test}

To obtain more detailed data regarding the effects of examined compounds on the process of clot formation and fibrinolysis CL-test was applied. The test is based on the evaluation of the global assay of coagulation and fibrinolysis by continuous measurements of the optical transmittance alterations and enables to establish the influence of tested compounds on the overall potential of clot formation and fibrinolysis as well as its kinetic parameters $(24,25)$.

General experimental conditions were presented previously $(24,26)$. Briefly, the measurements were taken at $\lambda=405 \mathrm{~nm}$ on a spectrophotometer (Cecil CE 2021, England) at $37^{\circ} \mathrm{C}$. Tested compounds at the concentrations of 3-fold $\mathrm{IC}_{50}$ value for MCF-7 cells (in a $10 \mu \mathrm{L}$ volume) and t-PA (220 $\mathrm{ng} / \mathrm{mL}$ ) were added to plasma diluted three times with TBS buffer, and the samples were incubated at $37^{\circ} \mathrm{C}$ for three minutes. Afterward, thrombin $(0.5$ $\mathrm{IU} / \mathrm{mL}$ ) in a volume of $10 \mu \mathrm{L}$ was added to initiate clot formation.

The obtained curves of clot formation and fibrinolysis were analyzed using dedicated software (25). The results were presented as mean $\pm \mathrm{SD} ; \mathrm{n}=4$.

The method of clot formation and fibrinolysis was validated, and the coefficient of variation (W) for single human plasma $(n=4)$ was within the range $1.9-8.3 \%$ depending on the calculated parameter.

\section{Red blood cells (RBCs) hemolysis}

The blood from healthy donors (Blood Donation Centre in Lodz) was collected to the tubes
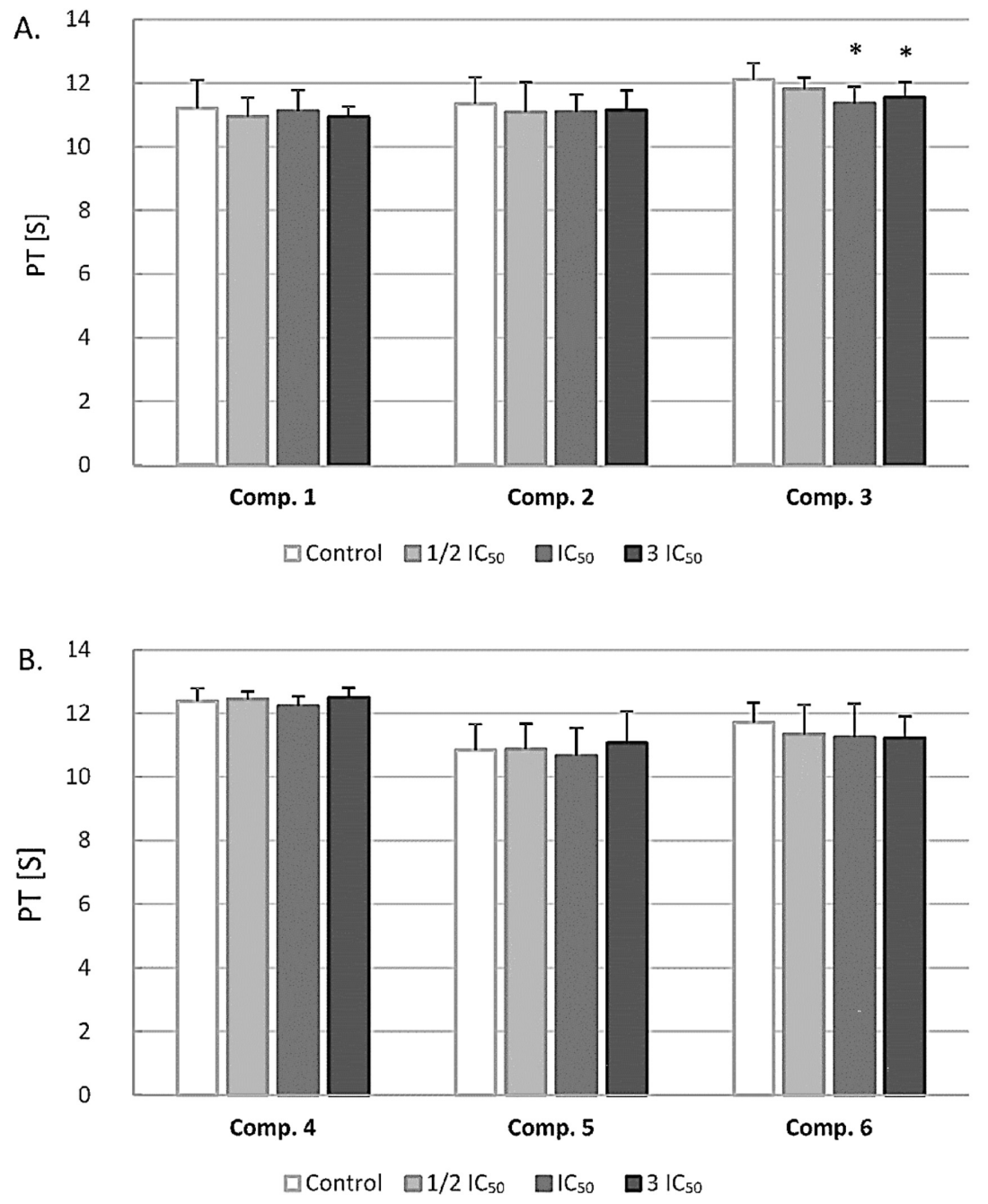

Figure 3. Effects of polyamine conjugates (A. - compounds $1-3$; B. - compounds $4-6$ ) on prothrombin time $(\mathrm{PT})(\mathrm{mean} \pm \mathrm{S} . \mathrm{D}$.; $\mathrm{n}=5)$ after 3 min incubation in plasma; final volume $160 \mu \mathrm{L} . * \mathrm{p}<0.05 \mathrm{vs}$. control. None of the tested compounds exerted a significant effect on PT value apart from compound 3 which at a concentration of 7.48 and $22.44 \mu \mathrm{M}$ statistically significantly shortened PT 

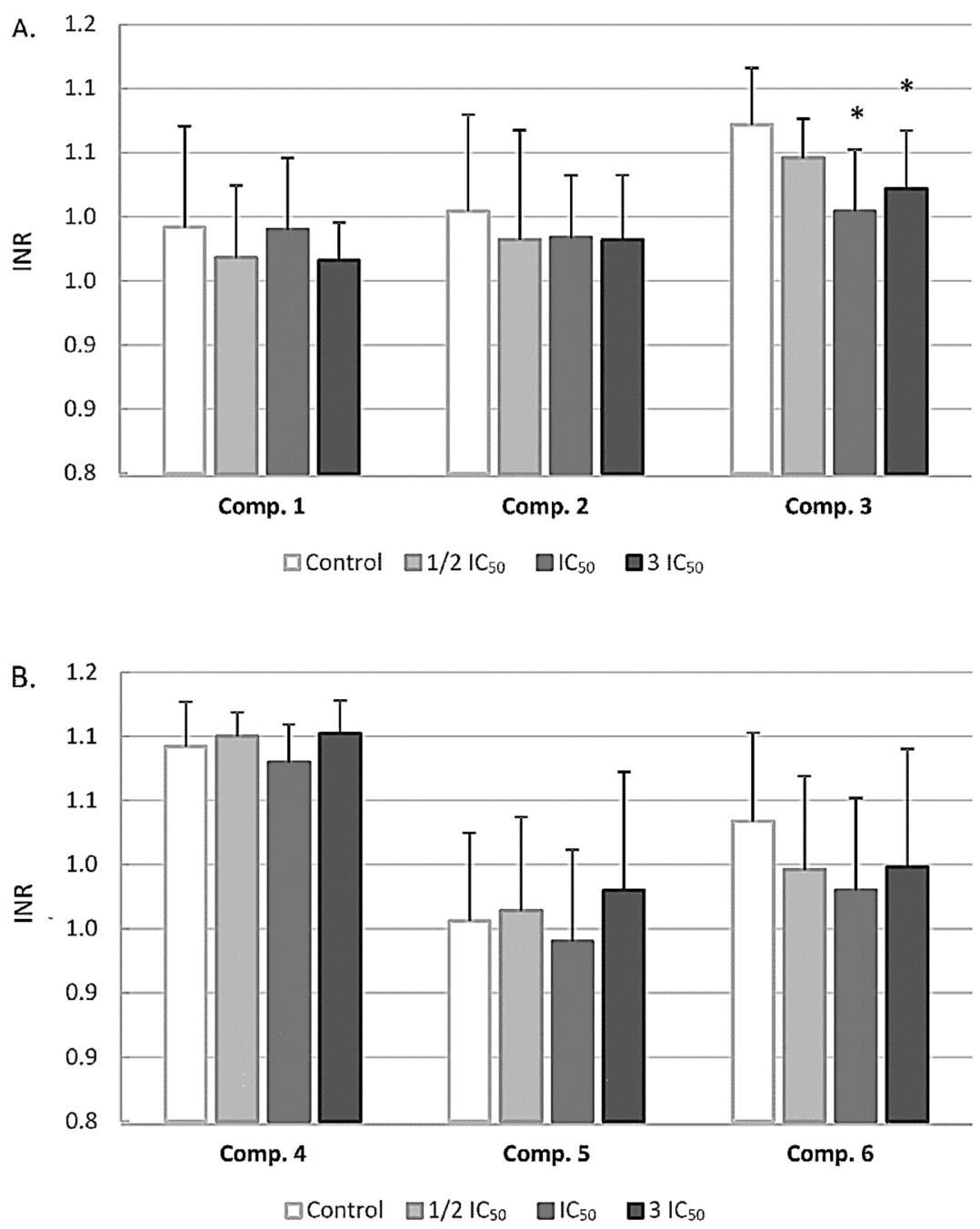

Figure 4. Effects of polyamine conjugates (A. - compounds 1-3; B. - compounds 4 - 6) on the international normalized ratio (INR) (mean \pm S.D.; $\mathrm{n}=5$ ) after 3 min incubation in plasma; final volume $160 \mu \mathrm{L} .{ }^{*} \mathrm{p}<0.05$ vs. control

containing a solution of potassium EDTA. RBCs were isolated by centrifugation $(3000 \times \mathrm{g}, 10 \mathrm{~min})$ at $20^{\circ} \mathrm{C}$ and washed three times with $0.9 \%$ saline.

The evaluation of compounds' effect on RBCs was performed with the method described earlier (26). The results were presented as a percentage of released hemoglobin. Positive (Triton X-100 (2.0\% $\mathrm{v} / \mathrm{v})$ ) and saline solution control were used which constituted $100 \%$ of hemoglobin release, and spontaneous hemolysis of RBCs, respectively (26), $\mathrm{n}=5$. The coefficient of variability was counted ( $\mathrm{W}=$ $9.51 \%, \mathrm{n}=5)$.

\section{Microscopy}

A $2 \%$ erythrocyte suspension was incubated at $37^{\circ} \mathrm{C}$ for $60 \mathrm{~min}$ with various concentrations of test- ed compounds. After this time, the suspension was diluted ten-fold on titration plates. The morphology of the RBCs was evaluated using a phase contrast (Opta-Tech, Poland) inverted microscope, at 400times magnification, equipped with software (OptaView 7) for image analysis.

\section{Statistics}

Statistical analysis was conducted with a commercially available package (Statistica 12.0, StatSoft). All results are presented as means \pm SD (standard deviation). Normal distribution of continuous variables was verified with the Shapiro-Wilk test. Paired t-test was used for intergroup comparisons of normally distributed variables, while the variables with non-normal distributions were com- 
pared using the Wilcoxon signed rank test. The results of all the tests were considered significant at p-values lower than 0.05 .

\section{RESULTS}

\section{Activated partial thromboplastin time (APTT)}

The stock solutions of compounds for coagulology studies were prepared in DMSO or water, depending on their solubility. The dilutions of stock solutions were prepared in water straightforward to the analysis and were stored up to $3 \mathrm{~h}$. In order to identify the effects of examined compounds on the activity of the intrinsic and common pathways of coagulation, we performed the APTT assay. Compounds were examined in the concentration corresponding to $1 / 2 \mathrm{IC}_{50}, \mathrm{IC}_{50}$ and $3 \mathrm{IC}_{50}$ values for MCF7 cell line. The results of the experiments are illustrated in Figure 2.

Incubation of plasma with compound $\mathbf{1}$ and $\mathbf{5}$ resulted in significant changes in the APTT value. Compound 5 at the highest concentration $(46.56 \mu \mathrm{M})$ contributed to the prolongation of APTT (32.52 s for control vs. approximately $34.92 \mathrm{~s}$ for the highest concentration of tested compound). In case of compound $\mathbf{1}$, we observed statistically significant shortening of APTT only for the lowest concentration used $(10.69 \mu \mathrm{M})$. For other compounds, we did not
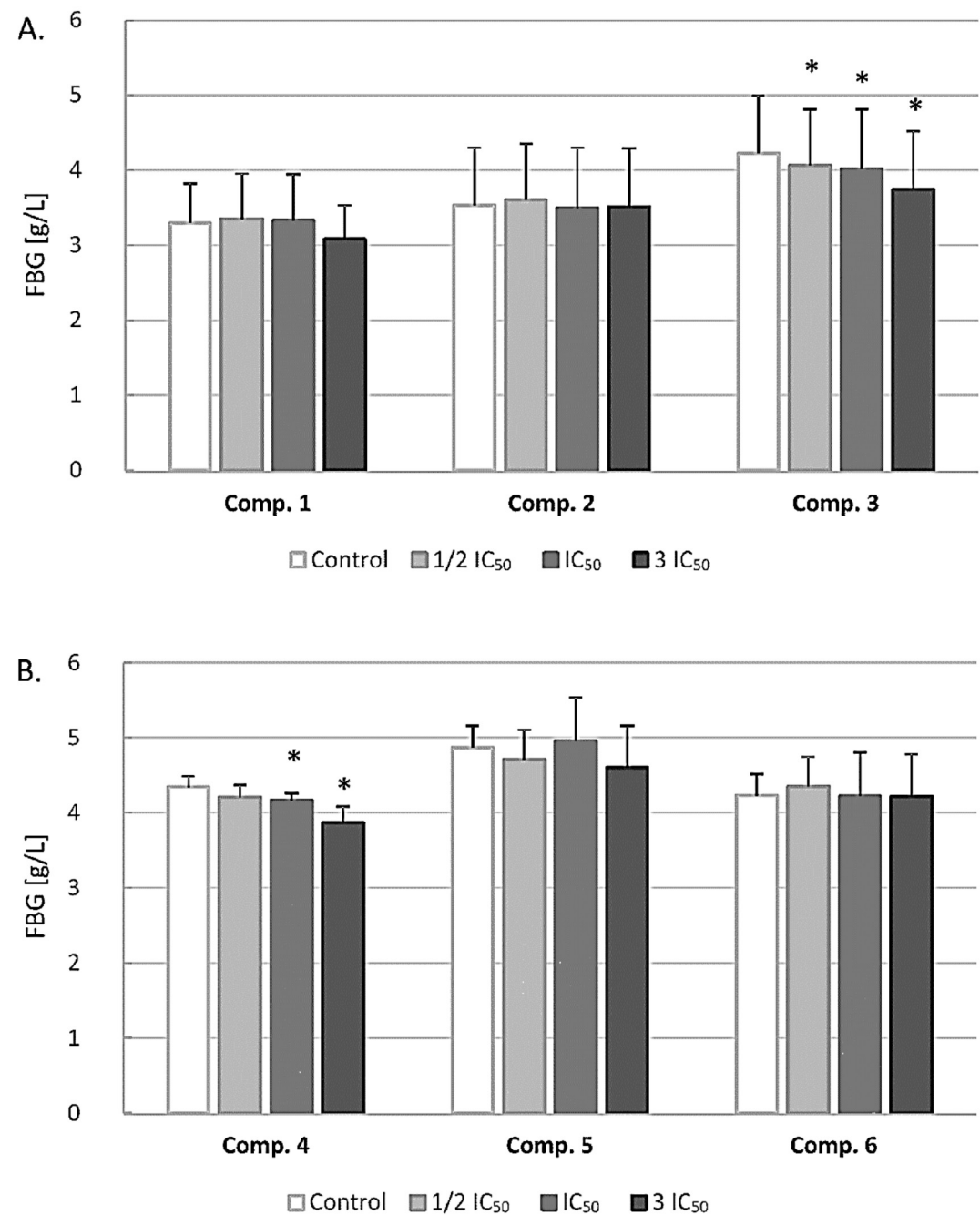

Figure 5. Effects of polyamine conjugates (A. - compounds 1-3; B. - compounds 4-6) on fibrinogen concentration (FBG) (mean \pm S.D.; $\mathrm{n}=5$ ) after 3 min incubation in plasma; final volume $160 \mu \mathrm{L}$. $* \mathrm{p}<0.05$ vs. control. Compounds 3 and 4 over the whole concentration range apart from the lowest one of $\mathbf{4}$ statistically significantly decreased FBG concentration whereas the rest of the examined compounds did not affect it 


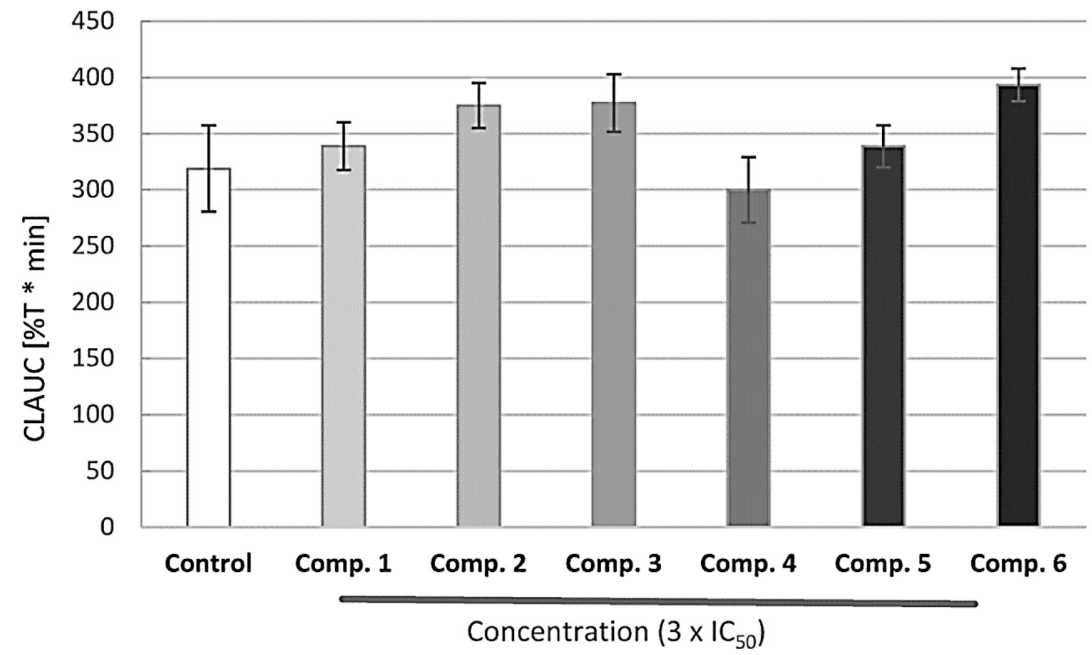

Figure 6. Influence of polyamine conjugates on overall potential of clot formation and lysis $\left(\mathrm{CL}_{\mathrm{AUC}}\right)$ after 3 min incubation in plasma; final volume $500 \mu \mathrm{L}$. None of the tested compounds exerted statistically significant effects on the overall potential of clot formation and fibrinolysis

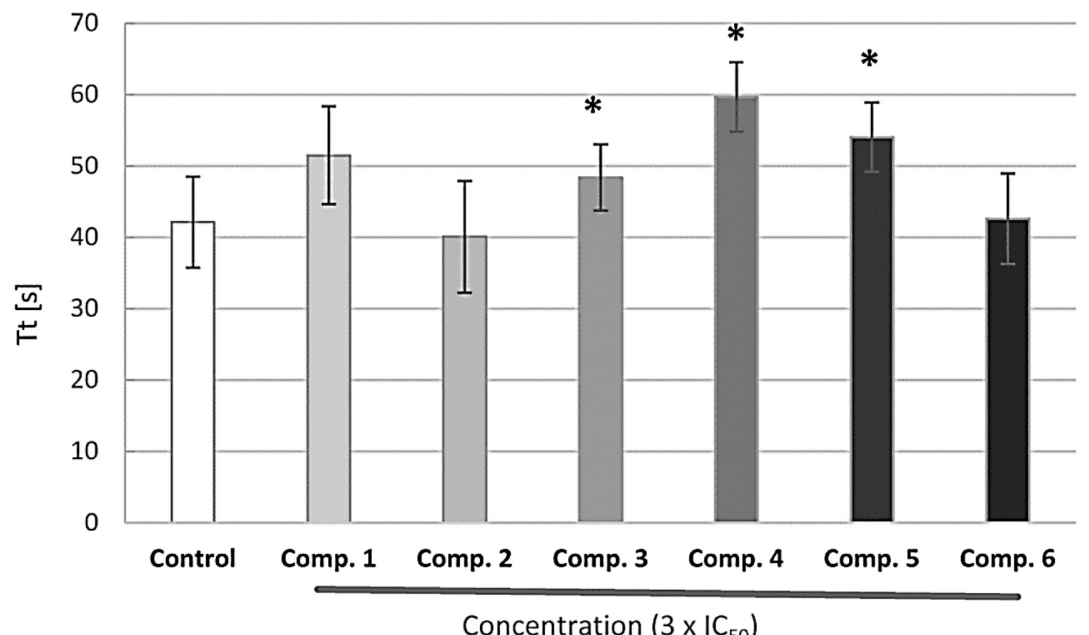

Figure 7. Influence of polyamine conjugates on thrombin time (Tt) after 3 min incubation in plasma; final volume $500 \mathrm{~mL}$; * p vs. control $<0.05$. Compounds $\mathbf{3}, \mathbf{4}$ and $\mathbf{5}$ at the concentrations reflecting 3 -fold of $\mathrm{IC}_{50}$ for MCF-7 cells significantly increased the value of this parameter $(\uparrow \mathrm{Tt})(\mathrm{p}=0.023,0.012,0.049$, respectively)

report any statistically significant changes in the APTT value.

\section{The prothrombin time (PT)}

The Prothrombin Time (PT) in contrast to the APTT gives evidence of the activity of the extrinsic and common pathways of coagulation. Polyamine conjugates' effects on PT are presented in Figure 3. Similarly to APTT studies statistical analysis in these experiments were conducted by comparison of tested samples with control samples containing water in a volume of $10 \mu \mathrm{L}$.

The results of the conducted experiments showed that only compound $\mathbf{3}$ at a concentration of 7.48 and $22.44 \mu \mathrm{M}$ statistically significantly short- ened PT which was reflected by decreased INR (Fig. 4). The rest of the examined polyamine conjugates did not exert any significant effect on PT.

In the case of fibrinogen (FBG) (Fig. 5), we found that compounds $\mathbf{3}$ and $\mathbf{4}$ over the whole concentration range apart from the lowest one of $\mathbf{4}$ statistically significantly decreased its concentration. Other compounds did not affect the FBG concentration.

\section{CL-test}

The effects of examined polyamine conjugates on the kinetic parameters of the process of clot formation, stabilization and fibrinolysis as well as the overall potential of clot formation and fibrinolysis are presented in Figures 6-11. Before the experi- 
ments, by 10 min incubation, we checked whether the tested compounds interact with human plasma. We did not report any visual precipitation or changes in the transmittance over this time. The aqueous solutions of compounds were prepared straight before the experiments out of water or DMSO stock solutions.

According to the obtained results presented in Figure 6, none of the tested compounds exerted statistically significant effects on the overall potential of clot formation and fibrinolysis $\left(\mathrm{CL}_{\mathrm{AUC}}\right)$. In case of the total time of the process $(\mathrm{T})$ we reported that compounds 1 at a concentration of $64.17 \mu \mathrm{M}$ and 6 at a concentration of $50.73 \mu \mathrm{M}$ contributed to its sta- tistically significant $(\mathrm{p}=0.039$ and 0.035 , respectively) prolongation $(\uparrow \mathrm{T})$.

Concerning the first phase of the examined process, we found that most of the tested compounds affected the kinetic parameters of clot formation. In case of thrombin time (Tt), which stands for the time elapsed from addition of thrombin to the beginning of coagulation, we reported that compounds $3, \mathbf{4}$ and 5 at the concentrations reflecting 3 -fold of $\mathrm{IC}_{50}$ for MCF-7 cells caused a significant increase in the value of this parameter $(\uparrow \mathrm{Tt})(\mathrm{p}=0.023,0.012$, 0.049 , respectively) (Fig. 7).

The results of the study revealed that only compound 2 increased the value of maximum clot-

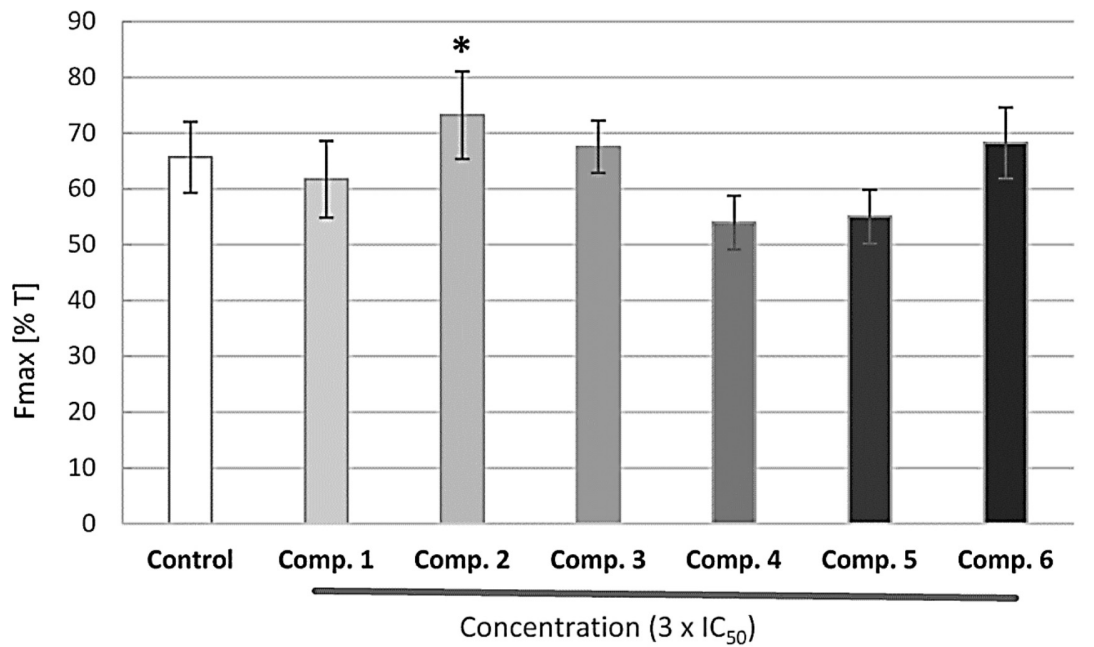

Figure 8. Influence of polyamine conjugates on maximum clotting (Fmax) after 3 min incubation in plasma; final volume $500 \mu \mathrm{L} ; * \mathrm{p}$ versus control $<0.05$. Only compound 2 increased the value of maximum clotting ( $\uparrow$ Fmax), $\mathrm{p}=0.038$. Rest of the examined compounds did not affect this parameter

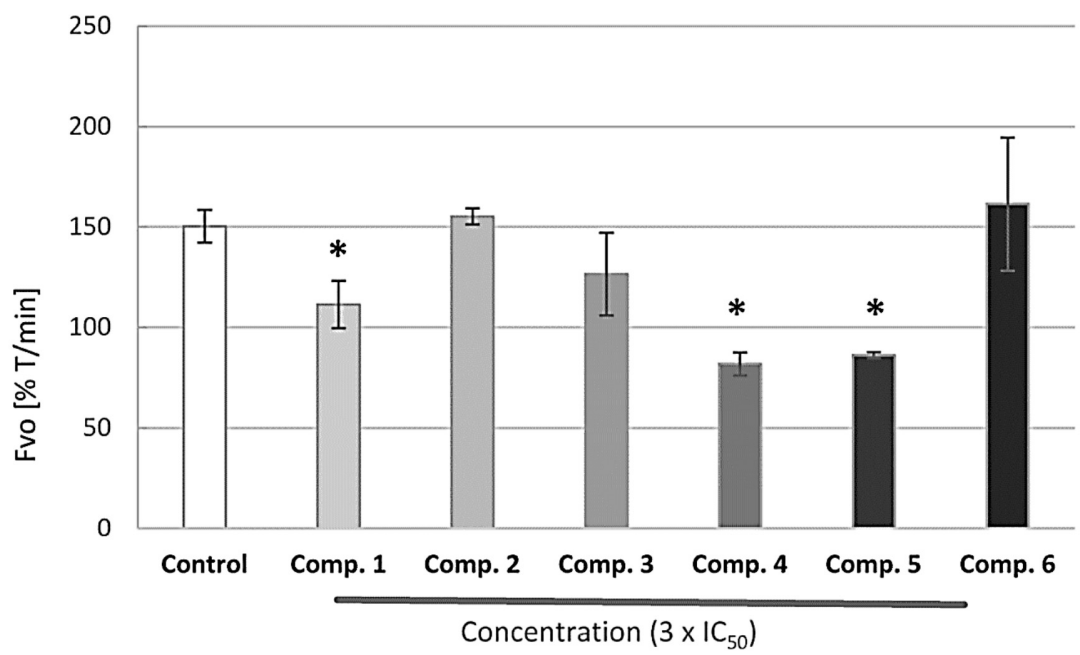

Figure 9. Influence of polyamine conjugates on initial plasma clotting velocity (Fvo) after 3 min incubation in plasma; final volume 500 $\mu \mathrm{L} ; *$ p versus control $<0.05$. Compounds $\mathbf{1}, \mathbf{4}$ and $\mathbf{5}$ significantly decreased the initial plasma clotting velocity $(\downarrow$ Fvo $), p=0.005,0.012$ and 0.006 , respectively. Rest of the examined compounds did not affect the Fvo value at administered concentrations 


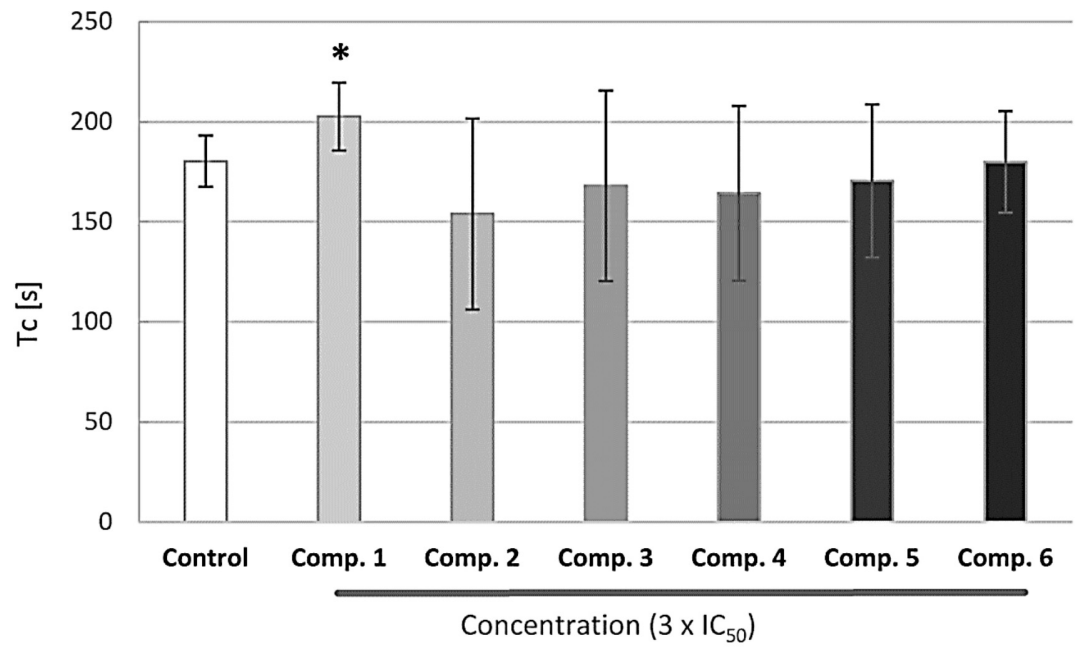

Figure 10. Influence of polyamine conjugates on clot stabilization time (Tc) after 3 min incubation in plasma; final volume $500 \mathrm{~mL}$; * vs. control $<0.05$. Compound 1 prolonged the clot stabilization time $(\uparrow \mathrm{Tc}), \mathrm{p}=0.010$. Rest of the examined compounds did not affect Tc at tested concentrations

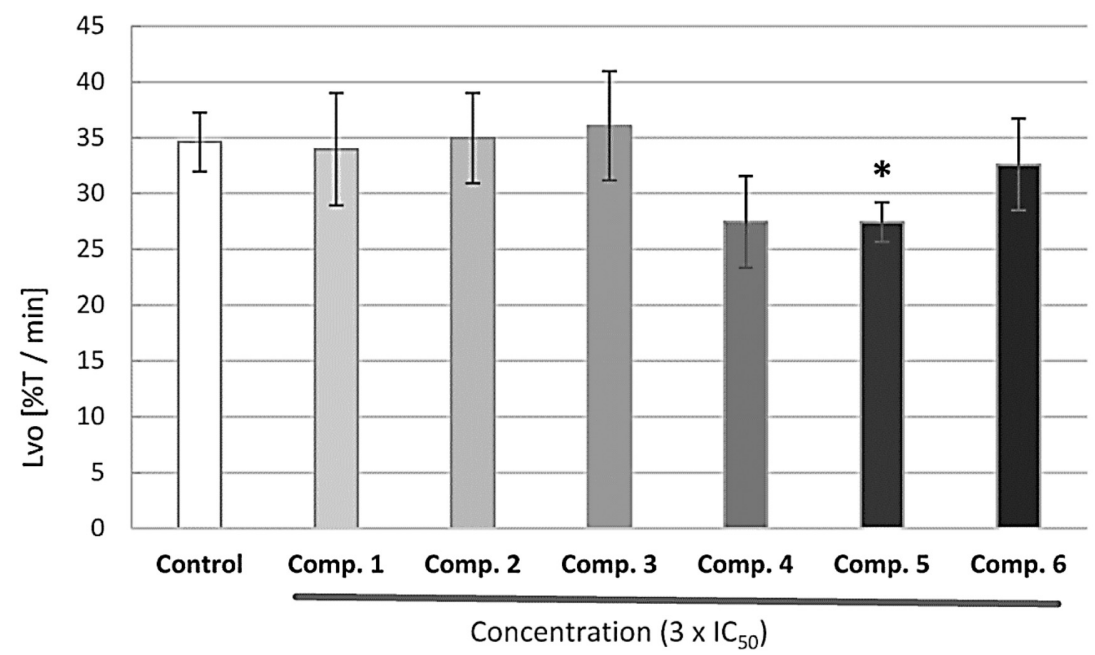

Figure 11. Influence of polyamine conjugates on initial clot fibrinolysis velocity (Lvo) after 3 min incubation in plasma; final volume 500 $\mu \mathrm{L} ; *$ p versus control $<0.05$. Only compound 5 at a concentration of $46.56 \mu \mathrm{M}$ decrease the initial clot fibrinolysis velocity $(\downarrow$ Lvo $), p=$ 0.026. Other examined compounds did not affect this parameter

ting ( $\uparrow$ Fmax) (Fig. 8), p = 0.038. According to the literature Fmax depends on fibrinogen level (27), however, for this compound we did not report any changes in FBG level, therefore it might imply that this compound influences the structure of the clot since Fmax depends also on the diameter of the individual filaments of fibrin (27).

As shown in Figure 9, compounds 1, 4 and 5 caused a significant decrease in the initial plasma clotting velocity ( $\downarrow$ Fvo), $p=0.005,0.012$ and 0.006 , respectively. These changes in Fvo were reflected by a significant increase in the plasma clotting time ( $\uparrow \mathrm{Tf}$ ). This relationship can be explained by the decreased activity of thrombin, thus it is of vital importance to examine the effects of these compounds on the amidolytic activity of thrombin. The rest of the tested compounds did not affect the Fvo value at administered concentrations.

In case of the second phase of the process, i.e. clot stabilization, only compound $\mathbf{1}$ was shown to affect the clot stabilization time ( $\uparrow \mathrm{Tc}), \mathrm{p}=0.010$ (Fig. 10). This result indicates that compound $\mathbf{1}$ may delay the process of fibrinolysis. We also reported that due to $\uparrow \mathrm{Tc}$, the area under the curve of stable clot formation was also statistically increased ( $\uparrow$ Sc). Regarding other compounds, we did not notice 
any statistically important changes at tested concentrations concerning these parameters which means that in in vivo conditions the previously formed clot does not persist longer in the vessel lumen (28).

The values of maximum lysis (Lmax) were related to the maximum clotting values (Fmax), indicating that the tested compounds contributed to the complete lysis of previously formed clots. Statistically significant changes were reported for compound 2 ( $\uparrow$ Lmax), $\mathrm{p}=0.048$.

Among tested polyamine conjugates, compound $\mathbf{5}$ was found to exhibit the most significant influence on the remaining parameters of fibrinolysis. When added at a concentration of $46.56 \mu \mathrm{M}$, compound $\mathbf{5}$ contributed to a decrease in the initial clot fibrinolysis velocity ( $\uparrow$ Lvo) (Fig. 11), p = 0.026, which was accompanied by prolonged fibrinolysis time $(\downarrow \mathrm{Tl})$. However, to provide the exact mechanism of action of this compound on the process of fibrinolysis, its effect on plasmin activity should be determined. According to the obtained results, other examined compounds did not affect the parameters of fibrinolysis.

\section{Red blood cells (RBCs) hemolysis}

The effects of examined compounds on the RBCs hemolysis are illustrated in Figure 12. Out of the tested compounds, $\mathbf{1}$ and $\mathbf{6}$ appear to be nontoxic to RBCs since the percentage of hemolysis did not change statistically significantly in comparison with spontaneous hemolysis (control). Exposure to 2, 3 and 5 was shown to significantly enhance the
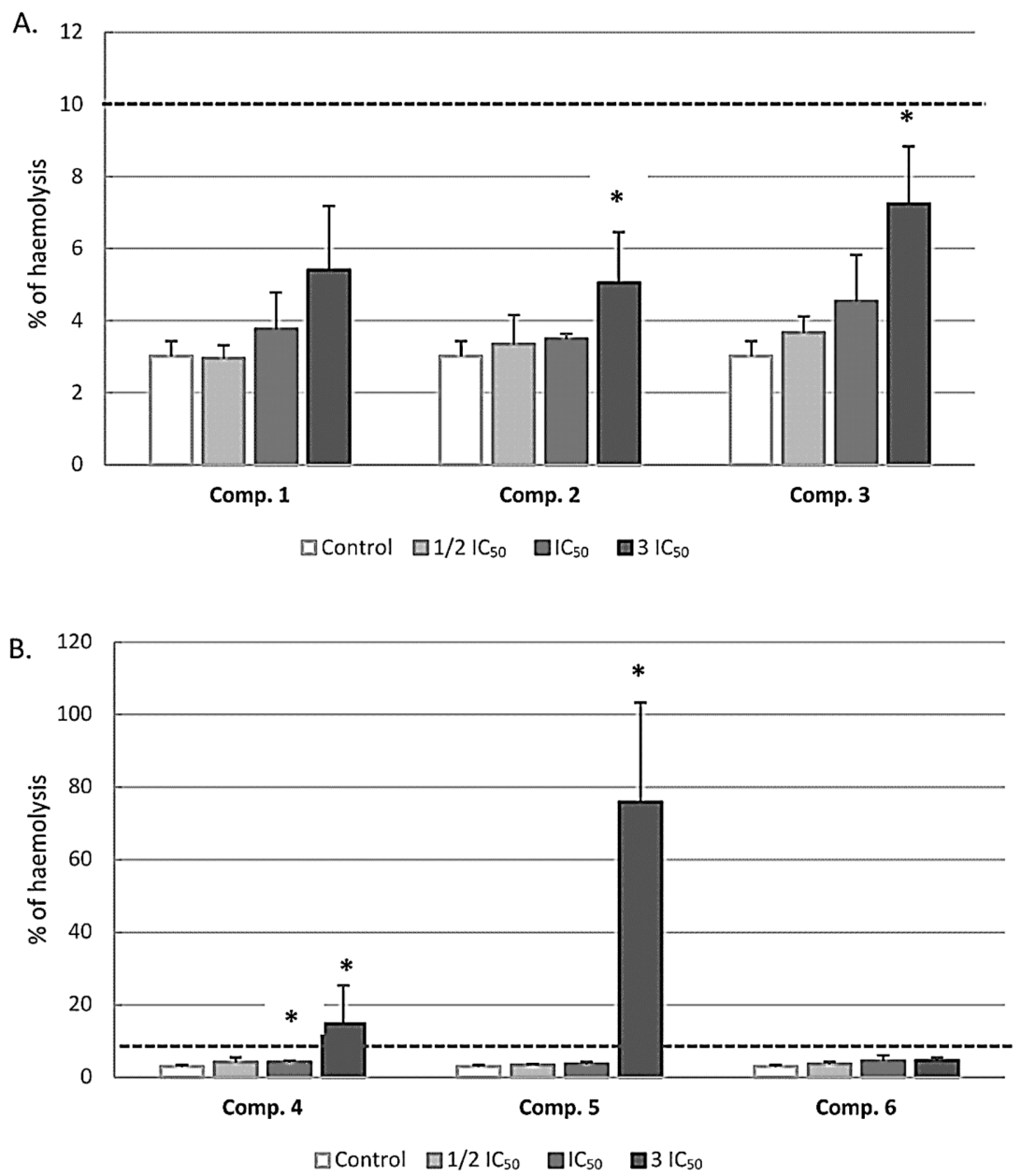

Figure 12. Percentage of hemolysis obtained from the interaction of polyamine conjugates (A. - compounds $\mathbf{1}-\mathbf{3} ; \mathrm{B}$. - compounds $\mathbf{4}-\mathbf{6}$ ) with $2 \%$ RBCs suspension, compared to the positive control Triton X-100 at $0.2 \%(100 \%$ hemolysis $)($ mean \pm S.D.; $n=5)$, $* p<0.05$ vs. control. Compounds 2, 3 and 5 significantly enhanced the process of RBCs lysis for the highest concentration tested (concentration 3-fold higher than $\mathrm{IC}_{50}$ value for MCF-7 cells). Compound $\mathbf{5}$ contributed to $75.92 \%$ hemolysis of RBCs at the concentration of $45.56 \mu \mathrm{M}$. The degree of hemolysis caused by compound 4 increased proportionally to its concentration, up to $4.20 \%$ and $14.77 \%$, at 6.0 and $18.0 \mu \mathrm{M}$, respectively 

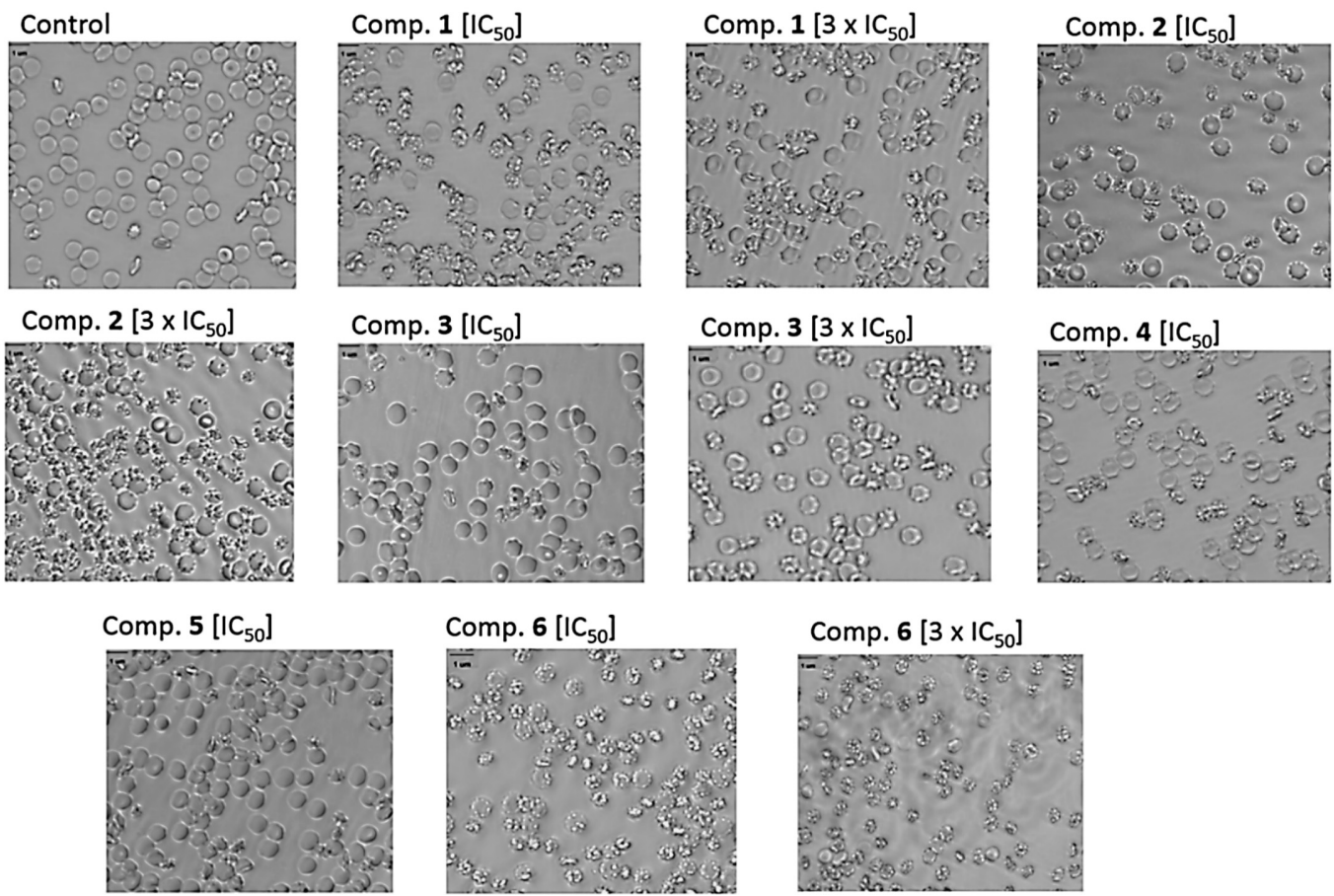

Figure 13. Effects of polyamine conjugates on the morphology of red blood cells in vitro. $2 \%$ erythrocyte suspension was treated at $37^{\circ} \mathrm{C}$ for $60 \mathrm{~min}$ with indicated concentrations of compounds $\mathbf{1}$ - 6. Representative phase-contrast images are shown (magnification of 400 times)

process of RBCs lysis for the highest concentration tested which constituted concentration 3-fold higher than $\mathrm{IC}_{50}$ value for MCF-7 cells. Among these compounds, the most toxic appears to be $\mathbf{5}$ which at a concentration of $45.56 \mu \mathrm{M}$ contributed to $75.92 \%$ hemolysis of RBCs. A significant increase in the rate of hemolysis was also documented for compound 4 even at the concentrations corresponding to the $\mathrm{IC}_{50}$ value for MCF-7 cells $(6 \mu \mathrm{M})$. The degree of hemolysis increased proportionally to the concentration of $\mathbf{4}$ up to $4.20 \%$ and $14.77 \%$, at 6.0 and 18.0 $\mu \mathrm{M}$, respectively.

\section{Microscopy}

The microscopic studies enabled the effects of polyamine conjugates on erythrocytes to be visualized (Fig. 13). While compounds 1 at both tested concentrations contributed to the formation of approximately $50 \%$ of eryptotic erythrocytes, compound $\mathbf{2}$ led to the same changes but in a concentration depending manner. At $18.54 \mu \mathrm{M}$ single eryptotic erythrocytes were observed and at higher concentration eryptosis constituted for more than $50 \%$. For compound $2, \mathrm{RBCs}$ in a form of echinocytes were also observed. Compound $\mathbf{6}$ at both tested concentrations contributed to the extensive eryptosis but also echinocytes were present. Compound $\mathbf{3}$ at lower concentration $(7.48 \mu \mathrm{M})$ led to the formation of single eryptotic erythrocytes, whereas at higher concentration $(22.4 \mu \mathrm{M})$ the eryptosis covered approximately $50 \%$ of RBCs. In the case of compound 4 and $\mathbf{5}$ single eryptotic RBCs were observed.

\section{DISCUSSION}

Designing potential anticancer drugs is a multifactorial and very difficult task. Preclinical assessment of their therapeutic activity and mechanism of action are essential goals, but in vitro evaluation of their influence on healthy tissues is of equal importance because it may shed light on the future safety of the therapy at the early stage of drug development. The aim of this study was to examine the influence of representative polyamine conjugates with bicyclic systems (1-6) on the process of coagulation and fibrinolysis and evaluate their effect on the healthy human erythrocytes (RBCs). Compounds were chosen on the basis of their biological properties described in our previous papers $(18,19$, 21, 29). Polyamine derivatives with chromane 1 and quinoline 2 scaffolds exhibited promising antiproliferative activity towards highly aggressive melanoma cell line A375 as well as breast cancer cell line MCF-7 whereas compounds with naphthalene $(\mathbf{3}, \mathbf{4})$ 
and indole $(\mathbf{5}, \mathbf{6})$ moieties caused 50\% growth inhibition at lower concentration in MCF-7and DU-145 cell lines in comparison to $\mathrm{PC}-3$ cell line. Therefore, the $\mathrm{IC}_{50}$ value for MCF-7 cell line was chosen as the reference point for the concentrations used in the current study.

Blood coagulation assays belong to the most frequently used tests to evaluate hemocompatibility of a newly synthesized compound or biomaterial (30). Blood coagulation is a local cascade process whereby soluble plasma proteins become activated in response to vascular injury, leading to the formation of a fibrin clot (31). In order to evaluate the influence of representative polyamine conjugates on the intrinsic pathway of coagulation, APTT assay was conducted. Only compounds $\mathbf{1}$ and $\mathbf{5}$ significantly changed the APTT value. Inhibition of intrinsic coagulation pathway by compound $\mathbf{5}$ illustrated by APTT prolongation (Fig. 2), may be an evidence of its anticoagulant properties. In the case of compound 1 at the concentration of $10.69 \mu \mathrm{M}$ shortening of APTT was observed but the obtained value was within the reference range $(28-39 \mathrm{~s})$.

As far as the influence of examined polyamine conjugates on extrinsic pathway of coagulation is concerned, only exposure to compound $\mathbf{3}$ at concentration 7.48 and $22.44 \mu \mathrm{M}$ resulted in statistically significant shortening of PT what was reflected by decreased INR, but, similarly to APTT, obtained values were enclosed within reference values (11 14 s, $0.9-1.2)$. As shown in Figure 3 other examined compounds did not influence the PT value. The rest of the examined polyamine conjugates did not exert any statistically significant changes in APTT value. Obtained results suggest that tested polyamine conjugates might be regarded as potentially biocompatible regarding plasma hemostasis.

Plasma fibrinogen level is also very important coagulation parameter with prognostic significance in many malignancies. The occurrence of hyperfibrinogenemia is correlated with tumor progression, metastasis and poor outcome (32-36). On the other hand, fibrinogen level changes are recognized as a possible biomarker for clinical response to chemotherapy in several cancers e.g. advanced breast cancer (37), penile cancer (38), esophageal cancer (39), rectal cancer (40) or non-small-cell lung cancer (41). Observed decreasing of FBG concentration by compounds 3 and 4 (Fig. 5) may result from the fact that these compounds might interact with the activated protein. However, during the incubation, we did not notice any visual changes in turbidity of the plasma samples after addition of tested compounds. It should also be highlighted that the decrease in
FBG level in the case of these two compounds was enclosed within the reference values.

Kinetic parameters of coagulation and fibrinolysis process were determined using an optical CLtest based on continuous measurement of transmittance alterations. Thrombin $(0.5 \mathrm{IU} / \mathrm{mL})$ and $\mathrm{t}-\mathrm{PA}$ $(220 \mathrm{ng} / \mathrm{mL})$ were used to obtain a clotting and lysis curve. As previously shown CL-test is a useful tool enabling evaluation of overall clot formation and fibrinolysis potential of various compounds (24-26).

Regarding polyamine conjugates, compounds $\mathbf{3}, \mathbf{4}$ and 5 at the concentrations reflecting 3-fold of $\mathrm{IC}_{50}$ for MCF-7 cells caused a significant increase in the value of thrombin time ( $\uparrow \mathrm{Tt}$ ) (Fig. 7) which may be an evidence of their anticoagulant properties. Only compound $\mathbf{2}$ increased value of maximum clotting Fmax (Fig. 8) but without changes in FBG level what might imply its influence on the structure of clot since Fmax depends also on the diameter of the individual filaments of fibrin (27).

Compounds 1, 4, 5 significantly decreased the initial plasma clotting velocity (Fvo) which was reflected by a significant increment of the plasma clotting time (Tf). This finding, together with prolongation of $\mathrm{Tt}$ might be caused by the inhibitory effect of these compounds on the amidolytic activity of thrombin.

Regarding the second phase of the process, only compound $\mathbf{1}$ may delay the process of fibrinolysis since it was shown to increase the clot stabilization time (Tc) as well as the area under the curve of stable clot formation ( $\uparrow \mathrm{Sc}$ ). Other compounds do not delay the process of fibrinolysis and do not affect the time elapsed between the initiation of the clotting and complete lysis of the clot. This is extremely important in the view of the fact that cancer disease is frequently associated with resistance to fibrinolysis $(42,43)$.

As depicted in Figure 6, none of the tested polyamine conjugates significantly influenced the overall potential of clot formation and fibrinolysis suggesting that they might be regarded as biocompatible concerning plasma hemostasis. The area under the clot formation and fibrinolysis curve $\left(\mathrm{CL}_{\mathrm{AUC}}\right)$ is an equivalent to overall hemostasis potential (OHP) and correlates with an increased risk of cardiovascular events (44). This finding is very important especially in the view of above-mentioned impaired hemostasis in cancer patients.

Besides the interactions of newly synthesized compounds with plasma proteins, a series of interactions with blood cells might be initiated. Pretorius et al. (45) indicated that erythrocytes are extremely sensitive cells, and although they do not have nuclei and 
mitochondria, form a crucial component of the human body as health indicators. Anticancer agents that enter the bloodstream under systemic chemotherapy can affect RBCs by inducing microrheological alterations (46) suppressing erythropoiesis as well as causing hemolysis e.g. tamoxifen (47), doxorubicin (48). Therefore, it is essential to assess the effect of newly developed drugs on RBCs. Generally, hemocompatibility is evaluated through hemolysis of RBCs, which is considered a simple and reliable measurement for estimating blood biocompatibility (49). Our studies of the in vitro response of RBCs to various concentrations of examined polyamine conjugates revealed a statistically significant increase in the rate of hemolysis for compound $\mathbf{4}$ and $\mathbf{5}$, but only at the highest concentrations tested constituting 3-fold $\mathrm{IC}_{50}$ value for MCF-7 cells (Fig. 12). For these two compounds, the hemolysis exceeded $10 \%$ which in clinical conditions is regarded as a toxicity limit (50). Compounds $\mathbf{1}$ and $\mathbf{6}$ were found to have no effect on the integrity of the erythrocyte membrane over the whole concentration range which resulted in lack of hemolysis. In turn, it was found that for compounds $\mathbf{2}$ and $\mathbf{3}$ the hemolysis was significantly higher in comparison with control, but according to Fisher only this exceeding $10 \%$ should be regarded as clinically important (50)

Light microscopy studies enabled the effect of polyamine conjugates on the morphology of RBCs to be evaluated. All compounds, depending on their concentration, contributed, in varying degrees, to the RBCs eryptosis. According to Lang et al. $(51,52)$ eryptosis is a process of programmed cell death similar to apoptosis. The process might be caused by hyperosmotic shock, energy reduction, or inflammatory markers that lead to oxidative stress or xenobiotics (e.g. anticancer drugs). Eryptosis is responsible for the removal of defective erythrocytes, the prevention of hemolysis and the release of concomitant hemoglobin. Another positive aspect of eryptosis is the fact that drugs contributing to eryptosis may favorably influence the clinical course of malaria by clearing infected erythrocytes from circulating blood (52). However, it should also be mentioned that drug-induced eryptosis may lead to erythropenia and anemia. Furthermore, eryptotic erythrocytes may also stimulate blood clotting, which, as a consequence, can impede microcirculation (52). Our microscopy studies showed also that compounds $\mathbf{2}$ and $\mathbf{6}$ contributed to physiological changes of erythrocytes as the echinocytes were visible. The conversion of biconcave RBCs into echinocytes depends on many factors including $\mathrm{pH}$, ionic strength, and the interaction of xenobiotics (53). Some drugs, via interaction with components of ery- throcyte membranes, may change the shape of the erythrocyte. Formation of echinocytes arises from the insertion of xenobiotic into the outer monolayer of erythrocyte membrane (54).

\section{CONCLUSION}

Experimental findings presented above indicate that examined polyamine conjugates with bicyclic systems (1-6) do not induce changes in both extrinsic and intrinsic coagulation pathway. In addition, they do not exert statistically significant effects on the overall potential of clot formation and fibrinolysis $\left(\mathrm{CL}_{\mathrm{AUC}}\right)$, suggesting that they might be regarded as biocompatible concerning plasma hemostasis in the concentration corresponding to $\mathrm{IC}_{50}$ values for MCF-7 cell line. Representative polyamine conjugates should generally be considered safe for use, and might be regarded as promising candidates for further in vitro and pre-clinical studies.

\section{Acknowledgment}

This study was supported by the Medical University in Lodz, Poland, Research Programme No 503/3-011-03/503-31-001 and 503/3-01501/503-31-004.

\section{REFERENCES}

1. Kvolik S., Jukic M., Matijevic M., Marjanovic K., Glavas-Obrovac L.: Surg. Oncol. 19, 33 (2010).

2. De Cicco M.: Crit. Rev. Oncol. Hematol. 50, 187 (2004).

3. Sousou T., Khorana A.A.: Arterioscler. Thromb. Vasc. Biol. 29, 316 (2009).

4. Velander A.J., DeAngelis L.M., Navi B.B.: Curr. Atheroscler. Rep. 14, 373 (2012).

5. Burbury K.: Best Pract. Res. Clin. Anaesthesiol. 27, 493 (2013).

6. Falanga A., Marchetti M., Vignoli A.: J. Thromb. Haemost. 11, 223 (2013).

7. Haddad T.C., Greeno E.W.: Thromb. Res. 118, 555 (2006).

8. Creutzig U., Zimmermann M., Reinhardt D., Dworzak M., Stary J. et al.: J. Clin. Oncol. 22, 4384 (2004).

9. Khorana A.A., Francis C.W., Culakova E., Kuderer N.M., Lyman G.H.: J. Thromb. Haemost. 5, 632 (2007).

10. Ma L., Francia G., Viloria-Petit A., Hicklin D.J., du Manoir J. et al.: Cancer Res. 65, 5365 (2005). 
11. Mitchell L.G., PARKAAGroup.: Cancer 97, 508 (2003).

12. Cuzick J., Forbes J.F., Sestak I., Cawthorn S., Hamed H. et al.: J. Natl. Cancer Inst. 99, 272 (2007).

13. Munter G., Hershko C.: Acta Haematol. 105, 97 (2001).

14. Malkhasyan K., Halene S., Lacy J.: Clin. Colorectal Canc. 14, 9 (2015).

15. Zangari M., Anaissie E., Barlogie B., Badros A., Desikan R. et al.: Blood 98, 1614 (2001).

16. Cavo M., Zamagni E., Cellini C., Tosi P., Cangini D. et al.: Blood 100, 2272 (2002).

17. Dimopoulos M.A., Eleutherakis-Papaiakovou V.: Am. J. Med. 117, 508 (2004).

18. Szulawska-Mroczek A., Szumilak M., Szczesio M., Olczak A., Nazarski R.B. et al.: Arch. Pharm. Chem. Life Sci. 346, 34 (2013).

19. Szumilak M., Szulawska-Mroczek A., Koprowska K., Stasiak M., Lewgowd W. et al.: Eur. J. Med. Chem. 45, 5744 (2010).

20. Szumilak M., Gałdyszyńska M., Domińska K., Bak-Sypien, I.I., Merecz-Sadowska A, et al.: Molecules. 22, 794 (2017).

21. Szumilak M., Gałdyszyńska M., Domińska K., Stańczak A., Piastowska-Ciesielska A.: Acta Biochim. Pol. 64, 307 (2017).

22. Szumilak M., Lewgowd W., Stańczak A.: Acta Pol. Pharm. 73, 1190 (2016).

23. Szumilak M., Merecz A., Strek M., Stańczak A., Inglot T.W. et al.: Int. J. Mol. Sci. 17, 1560 (2016).

24. Markowicz-Piasecka M., Łuczak E., Chałubiński M., Broncel M., Mikiciuk-Olasik E. et al.: Int. J. Pharm. 473, 158 (2014).

25. Kostka B., Para J., Sikora J.: Blood Coagul. Fibrinolysis 18, 611 (2007).

26. Markowicz-Piasecka M., Mikiciuk-Olasik E., Sikora J.: Pharmacol. Rep. 67, 1230 (2015).

27. Standeven K.F., Ariens R.A.S., Grant P.J.: Blood Rev. 19, 275 (2005).

28. Antovic A.: Semin. Thromb. Hemost. 36, 772 (2010).

29. Balan V., Verestiuc L.: Eur. Polym. J. 53, 171 (2014).

30. Dawids S.: in Test Procedures for the Blood Compatibility of Biomaterials: Haemocompatibility, What Does It Mean?, Dawids S. Ed., Chapter 1, p. 3-11 Springer Netherlands, Dordrecht 1993.

31. Guo Q.Q., Zhang B., Dong X., Xie Q.P., Guo E.Q. et al.: Pancreas. 38, 75 (2009).
32. Yamashita H., Kitayama J., Taguri M., Nagawa H.: World J. Surg. 33, 1298 (2009).

33. Yamashita H., Kitayama J., Kanno N., Yatomi Y., Nagawa H.: BMC Cancer 6, 147 (2006).

34. Polterauer S., Grimm C., Seebacher V., Concin N., Marth C., Tomovski C. et al.: Oncologist 14, 979 (2009).

35. Hu K., Wang Z., Lin P., Wen Z., Sun L. et al.: Oncotarget 8, 43130 (2017).

36. Mei Y., Liu H., Sun X., Li X., Zhao S. et al.: Tumor Biol. 39, 1010428317700002 (2017).

37. Ma C., Zhou Y., Zhou S., Zhao K., Lu B. et al.: Oncotarget 8, 12355 (2017).

38. Matsuda S., Takeuchi H., Fukuda K., Nakamura R., Takahashi T. et al.: Dis. Esophagus 27, 654 (2014).

39. Kawai K., Kitayama J., Tsuno N.H., Sunami E., Nagawa H.: Int. J. Colorectal. Dis. 26, 45 (2011).

40. Zhao J., Zhao M.F., Jin B., Yu P., Hu X.J. et al.: BMC Cancer 12, 330 (2012).

41. Gronostaj K., Richter P., Nowak W., Undas A.: Prz. Gastroenterol. 11, 104 (2016).

42. Wojtukiewicz M.Z., Zacharski L.R., Memoli V.A.: Cancer 65, 481 (1990).

43. He S., Antovic A., Blomback M.: Thromb. Res. 103, 355 (2001).

44. Pretorius E., du Plooy J.N., Bester J.: Cell Physiol. Biochem. 39, 1977 (2016).

45. Muravyov A.V., Tikhomirova I.A., Kislov N.V., Petrochenko A.S.: J. Cell Biotech. 1, 151 (2016).

46. Cruz Silva M.M., Madeira V.M., Almeida L.M., Custódio J.B.: BBA Biomembranes 1464, 49 (2000).

47. Shinohara K., Tanaka K.R.: Hemoglobin 4, 735 (1980).

48. Zhou H.Y., Zhang Y.P., Zhang W.F., Chen X.G.: Carbohydr. Polym. 83, 1643 (2011).

49. Fischer D., Li Y.X., Ahlemeyer B., Krieglstein J., Kissel T.: Biomaterials 24, 1121 (2003).

50. Lang E., Qadri S.M., Lang F.: Cell Biol. 44, 1236 (2012).

51. Lang F., Qadri S.M.: Blood Purif. 33, 125 (2012).

52. Diez-Silva M., Dao M., Han J.Y., Lim C.T., Suresh S.: MRS Bull. 35, 382 (2010).

53. Sheetz M.P., Singer S.J.: Proc. Natl. Acad Sci. USA 71, 4457 (1974).

Received: 14.09. 2017 